\title{
The Effects of Smoking on the Osmotic Pressure of Human Dental Pulp Tissue
}

\author{
Ebru Özsezer Demiryürek ${ }^{a}$ Elif Eser Sakallıoğlu ${ }^{b}$ Elif Kalyoncuoğlu ${ }^{a}$ \\ Yeliz Yılmaz Miroğluc Umur Sakallıŏlu ${ }^{\mathrm{b}}$ \\ Departments of a Endodontics, ${ }^{b}$ Periodontology and ${ }^{\mathrm{c}}$ Molecular Biology, Faculty of Science, Ondokuz Mayıs \\ University, Samsun, Turkey
}

\section{Key Words}

Smoking · Dental pulp · Osmotic pressure · Fluid dynamics · Pulpal disease

\begin{abstract}
Objective: We aimed to investigate the effect of smoking on the osmotic pressure (OP) of human dental pulp tissue. Materials and Methods: Sixty male dental patients (smokers and nonsmokers) scheduled for root canal treatment for prosthodontics were included in the study. Fifteen patients (1 premolar tooth/patient) were allocated to each of the following groups according to their smoking habits, i.e. group $1: \leq 10$ cigarettes/day, group 2: 11-20 cigarettes/day, group 3: >20 cigarettes/day and group 4: nonsmoking controls. Apical pulp tissues were removed via coronal access. Pulp tissue supernatants were obtained to measure the pulpal OP by means of a semimicro digital osmometer. One-way analysis of variance and the post hoc Duncan test were used to analyze the differences in OP between groups. Regression analysis was used to determine the relationship between the number of cigarettes smoked daily and the pulpal OP. $\boldsymbol{R e}$ sults: The mean ( \pm SD) OP value decreased as cigarette consumption increased: group $4(268.00 \pm 10.09 \mathrm{mosm} / \mathrm{kg})>$ group $1(259.20 \pm 7.16 \mathrm{mosm} / \mathrm{kg})>$ group $2(248.90 \pm 2.23$ $\mathrm{mosm} / \mathrm{kg})>$ group $3(239.90 \pm 7.40 \mathrm{mosm} / \mathrm{kg})$. The OP dif-
\end{abstract}

fered significantly between groups ( $p<0.01$ ), and a significant negative correlation was found between cigarette consumption and pulpal OP $(r=-0.809, p<0.01)$. Conclusion: In this study, the OP decreased as the number of cigarettes smoked increased. In clinical examination, there may be misdiagnosis of pulpal conditions in smokers (even in healthy pulp tissue) due to the effect of altered OP on pulpal tissue reactions.

(c) 2015 S. Karger AG, Basel

\section{Introduction}

Structural and functional modifications of the vascular system are among the principal impacts that smoking has on the body [1]. The effects of smoking have been attributed to the impairment of certain immune responses and complexes such as impaired phagocytosis, chemotaxis of neutrophils, production of protease inhibitors and prostaglandin $\mathrm{E}_{2}$ and generation of free radicals in healthy and diseased tissues $[2,3]$. Vascular changes, the increased permeability of the vascular tissue wall and increased osmotic pressure (OP) are welldefined processes of tissue inflammation that lead to an imbalance in tissue homeostasis [4]. Smoking can alter the vascular structure and microvascular permeability

\begin{tabular}{|c|c|}
\hline KARGER 125 & $\begin{array}{l}\text { (c) } 2015 \text { S. Karger AG, Basel } \\
1011-7571 / 15 / 0245-0465 \$ 39.50 / 0\end{array}$ \\
\hline $\begin{array}{l}\text { E-Mail karger@karger.com } \\
\text { www.karger.com/mpp }\end{array}$ & $\begin{array}{l}\text { This is an Open Access article licensed under the terms of the } \\
\text { Creative Commons Attribution-NonCommercial 3.0 Un- } \\
\text { ported license (CC BY-NC) (www.karger.com/OA-license), } \\
\text { applicable to the online version of the article only. Distribu- } \\
\text { tion permitted for non-commercial purposes only. }\end{array}$ \\
\hline
\end{tabular}

Ebru Özsezer Demiryürek, Associate Professor Department of Endodontics

Faculty of Dentistry, Ondokuz Mayis University

TR-55139 Samsun (Turkey)

E-Mail eozsezer@omu.edu.tr 
[5-7] and also cause vasoconstriction [7]. The constriction of vessels supplying blood to the tissues causes a reduction in blood flow [8]. Hence, smoking may alter the fluid dynamics of any healthy tissue, potentially leading to altered physiological processes that may cause inflammatory responses and/or pain mediation in the tissues.

$\mathrm{OP}$ is an important component of the Starling forces [9] and determines the rate and volume of fluid flowing from the vessels into the interstitium [10]. Under ordinary conditions, tissues exhibit a positive capillary filtration pressure leading to the filtration of fluid from the vessels into the interstitium $[4,9]$. Pulpal OP results from hydrostatic pressure in the interstitial fluid surrounding the pulp cells and is affected by blood flow, blood pressure and interstitial volume [10]. Altered pulpal OP may cause a different tissue response (and therefore altered clinical signs) in pulp following even small fluid alterations. Currently, sufficient data on the fluid dynamics of healthy pulp tissue are not available and the effects of systemic situations, e.g. smoking, on pulpal fluid dynamics, have not yet been determined.

To date, no study has investigated the impact of smoking on pulpal OP reflecting the pulpal tissue response in smokers. Thus, the aim of this study was to investigate OP alterations in the dental pulp tissue of smokers with no systemic conditions.

\section{Materials and Methods}

\section{Study Group Characterization}

This study was performed at the Departments of Endodontics and Periodontology in the Ondokuz Mayis University Dental Faculty, Samsun, Turkey. The study was approved by the Human Ethical Committee of the university, and informed consent was obtained from the participants. The study protocol was carried out according to the Helsinki Declaration of 1975 as revised in 2002. Sixty men (smokers and nonsmokers with an age range of $30-45$ years) undergoing root canal treatment on premolar teeth for prosthodontic reasons were enrolled in the study. A smoking status of 5-year duration was considered and the patients were allocated according to their smoking habits to constitute the study groups, i.e. group 1: $\leq 10$ cigarettes/day, group 2: 11-20 cigarettes/day, group 3: $>20$ cigarettes/day and group 4: patients who had never smoked formed the negative control group. The sample was sized for 5\% significance and 90\% power levels. Inclusion criteria were an age of least 30 years and healthy pulp in the premolars. Exclusion criteria were dental and/or periodontal problems and systemic problems and regular or current chemotherapeutic regimens (within 10 days prior to data collection). The clinical examination to determine periodontal status included: (1) the Silness-Löe plaque index [11], (2) the Löe-Silness gingival index [12], (3) the probing pocket depth and (4) the clinical
Table 1. Periodontal status of the study groups

\begin{tabular}{lllll}
\hline & PI & GI & PPD, mm & CAL, mm \\
\hline Group 1 & $0.3(0-2)$ & $0(0-2)$ & $1.74(1-4)$ & $1.74(1-4)$ \\
Group 2 & $0.5(0-1.2)$ & $0(0-2)$ & $1.83(1-3)$ & $1.83(1-3)$ \\
Group 3 & $0.3(0-2)$ & $0(0-2)$ & $1.66(1-2)$ & $1.66(1-2)$ \\
\hline
\end{tabular}

Values are given as a median (range). CAL $=$ Clinical attachment level; GI = Löe-Silness gingival index; $\mathrm{PI}$ = Silness-Löe plaque index; $\mathrm{PPD}=$ probing pocket depth.

attachment level with a radiographical evaluation of alveolar bone loss. Each status was measured at 6 sites (mesio-, mid- and disto- of both the buccal/labial and palatal/lingual surfaces) per tooth using a Williams periodontal probe. Patients with $\leq 1$ on the Löe-Silness gingival index, $<1$ on the the Silness-Löe plaque index, a probing pocket depth of $<3 \mathrm{~mm}$ and a clinical attachment level without radiographical evidence of alveolar bone loss in the entire mouth were regarded as periodontally healthy. The clinical diagnosis of pulpal health included: (1) no dental cavitation or caries, (2) a positive vitality test, (3) no pain history or sensitivity on palpation, (4) no sensitivity on horizontal and vertical percussions, (5) no crown or root resorptions on radiography, (6) no tooth apex alterations on radiography and (7) no widened periodontal spaces and a lamina dura that was intact on radiography. Pulpal tissues were harvested and OP levels were measured.

\section{Pulp Tissue Sampling}

Following administration of local anesthesia (2\% lidocaine with adrenaline 1:80,000), each tooth was isolated with a rubber dam. A standard coronal access opening was prepared using a sterile tungsten carbide round bur in a high-speed handpiece with a constant water spray. Pulp tissue was then removed with a sterile barbed broach. All samples were immediately placed in Eppendorf tubes filled with $1.5 \mathrm{ml}$ of $0.25 \mathrm{M}$ sucrose and stored at $-80^{\circ} \mathrm{C}$ until laboratory procedures were conducted. The samples were collected by a single blinded investigator (E.K.).

\section{Tissue Preparation and OP Measurement}

Pulp samples were processed to obtain tissue supernatants by homogenizing (four 30-second iterations at 20,500 rpm), freezethawing, ultrasonicating (four 30-second iterations at $5 \mu \mathrm{m}$ ) and ultracentrifuging $(20 \mathrm{~min}$ at $17,000 \mathrm{rpm})$. Pulpal OP was measured in these supernatants by a method described elsewhere [6]. We used a semimicro digital osmometer (Digital Automatic Osmometer, Knauer-ASI, Berlin, Germany) which involves a sensitive and practical measurement technique in intraoral tissues, even with small fluid samples [13, 14]. Before measurement, 0.15 $\mathrm{ml}$ of supernatant was placed in a clean, dry measuring vessel using a clean, dry pipette and placed into the adaptor of the osmometer. The measuring head was placed in the cooling cavity of the system and the OP was measured in mosm $/ \mathrm{kg}$ by cooling and crystallization in the first step and warming to $20^{\circ} \mathrm{C}$ in the final step. A single blinded investigator (Y.Y.M.) conducted all procedures. 
Table 2. Descriptive and comparative statistics of OP among the groups

\begin{tabular}{lllll}
\hline & \multicolumn{2}{l}{ OP, mosm/kg } & \\
\cline { 2 - 5 } & $\mathrm{n}$ & mean \pm SD & range & p value \\
\hline Group 1 ( $\leq 10$ cigarettes/day) & 15 & $259.20 \pm 7.16^{\mathrm{b}}$ & $249.00-271.00$ & \\
Group 2 (11-20 cigarettes/day) & 15 & $248.90 \pm 2.23^{\mathrm{c}}$ & $245.00-252.00$ & $<0.0001$ \\
Group 3 (>20 cigarettes/day) & 15 & $239.90 \pm 7.40^{\mathrm{d}}$ & $228.00-249.00$ & \\
Group 4 (nonsmoking controls) & 15 & $268.00 \pm 10.09^{\mathrm{a}}$ & $254.00-286.00$ & \\
\hline
\end{tabular}

There were 60 patients divided into 4 groups of 15 each.

a-d Statistically significant differences $(\mathrm{p}<0.0001)$ between the groups: group $4>$ group $1>$ group $2>$ group 3 .
Statistical Analysis

One-way analysis of variance (ANOVA) and the post hoc Duncan test were utilized to analyze differences between groups in terms of OP. The relationship between cigarette consumption and pulpal OP was determined using regression analysis. Statistical analyses were performed using SPSS v17.0 (SPSS Inc., Chicago, Ill., USA).

\section{Results}

The mean age of the patients was $36.82 \pm 4.54$ years. The sample size was set at 15 in each group. Demographic data are given in table 1 . No statistical difference was found in the periodontal status of the 4 groups ( $p>0.05$ ), and the ANOVA and post hoc Duncan tests showed no statistical differences in age $(\mathrm{p}>0.05)$. There was also no correlation between age and OP $(r=-0.195, \mathrm{p}>0.05)$. On the other hand, the difference in OP across groups was statistically significant ( $\mathrm{p}<0.0001)$, in a decreasing order of $268.00 \pm 10.09 \mathrm{mosm} / \mathrm{kg}$ in group $4,259.20 \pm 7.16$ $\mathrm{mosm} / \mathrm{kg}$ in group $1,248.90 \pm 2.23 \mathrm{mosm} / \mathrm{kg}$ in group 2 and $239.90 \pm 7.40 \mathrm{mosm} / \mathrm{kg}$ in group 3 (table 2 ). In addition, a strong and significant negative correlation was found between cigarette consumption and OP $(\mathrm{p}<0.01$, $r=-0.809$; fig. 1), indicating that the amount of smoking was negatively correlated to OP.

\section{Discussion}

This study demonstrated that the mean pulpal OP was significantly higher in nonsmokers than in smokers. The $\mathrm{OP}$ in pulp tissue decreased as the severity of smoking increased. Apparently, a decrease in OP can lead to a decreased blood flow to the pulp, as shown previously in other conditions [15-17]. In the fingers of smokers, a smoking-induced reduction in skin blood flow was de-

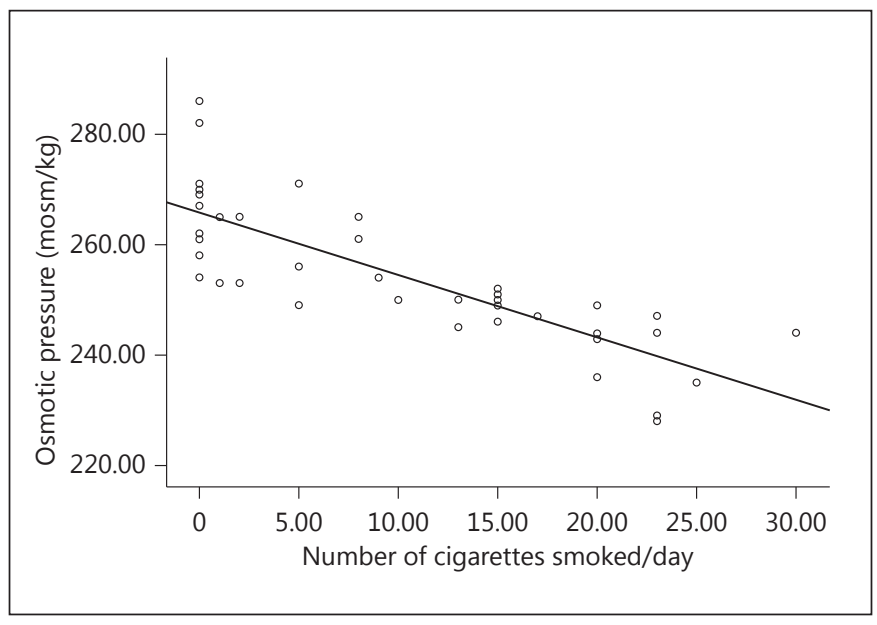

Fig. 1. Correlation between cigarette consumption and pulpal OP.

tected that caused vasoconstriction [16]. It has also been reported that smoking causes a reduction in the gingival blood flow [17]. The effect of smoking on blood flow in the dental pulp by measuring the OP in the tissue has not been studied before. However, earlier studies have examined the effects of nicotine on blood flow to other tissues. Our findings are parallel to these studies in reporting a decreased blood flow in the tissues in smokers.

It has been reported that blood flow in the dental pulp is regulated by neuronal, local and humoral mechanisms [18] but that the effect of systemic blood pressure on pulpal blood flow is more prominent than that of local mechanisms [19]. However, smoking may have both local and systemic effects on pulpal blood flow. When tobacco smoke comes into direct contact with the oral tissues, it delivers an array of chemical pollutants into the buccal cavity, such as nicotine, carbon monoxide and hydrogen cyanide [20]. Locally, smoking has a vasoconstrictive effect on the vessels, resulting in reduced blood 
flow in the tissue. Nicotine causes the release of catecholamines (adrenaline, noreadrenaline and isoprenaline) via stimulation of the sympathetic ganglion, adrenal medulla and sympathetic nerve endings. In general, nicotine administration is thought to exhibit a peripheral vasoconstrictive action [7]. In a previous study, it was reported that the constriction of vessels that supply blood to the tissue caused a reduction in blood flow with 2 weeks of nicotine treatment [8]. In addition, a preliminary study found that one of the neuropeptides, calcitonin gene-releated peptide (CGRP), affects pulpal blood flow and pulpal inflammation, which was significantly higher in the pulp of smokers than nonsmokers [21]. These findings indicate that smoking causes degenerative changes in the systemic circulation and the autonomic nervous system, which may lead to changes in homeostasis in the dental pulp and affect the normal functioning of pulpal tissue.

We should note that, other factors, such as the anesthetic used, age, sex and postural changes, can all affect pulpal blood flow. In our study, pulpal tissue was taken from human premolars of patients anesthetized with $2 \%$ lidocaine and adrenaline 1:80,000. It indicated that it was possible that the low pulpal OP in the smoker groups could be attributed to the vasoconstriction of pulpal tissue not only because of the local effect of adrenaline, but also because of the systemic effect of nicotine stimulating the release of adrenaline, as has been reported previously $[7,22]$. However, in our study, factors such as the anesthetic used, age, and sex were fixed and consistent in all groups. The systemic and local effects of the anesthetic were the same for all groups, so the changes in the OP were most likely related to cigarette consumption. Our study also supports the findings of a recent study suggesting that the autonomic nervous system plays a role in the regulation of blood flow in human dental pulp via postural changes [23]. It was shown that pulp blood pressure will change according to the heart rate and systemic circulation and advised that systemic diseases result in degenerative changes in pulpal conditions.

The vascular response of dental pulp plays an essential role in mediating dental pain and other inflammatory responses. Vasoconstriction and decreased blood flow [24] may also alter pain sensation in a tooth and the sensibility of the pulpal myelinated fibers. OP collectively interacts with vascular permeability and blood flow in this process, so a decrease in pulpal OP may also affect the development and severity of dental pain [22]. Nicotine creates vasoconstriction and ischemia in any healthy tissue. Under ischemic conditions, the normal clearance effect of blood flowing through the tissue is also reduced, possibly endangering the viability of the pulp, with early signs of inflammation [25]. Similarly, the effects of smoking on periodontal tissue can make it more difficult to detect the early stages of disease [3]. It has been reported that the perception of sharp pain is reduced when ischemia is created in healthy pulp [26]. A previous study found that when the volume of blood flow was reduced, vessels were likely to show signs of vascular dysfunction, restricting the supply of nutrients and impeding cellular repair. The authors suggested that smoking may be a factor that contributes to early tissue death within the pulp cavity [27]. Thus, smokers may display unusual clinical symptoms and signs compared to nonsmokers due to altered dental pain and inflammatory conditions.

A limitation of our study is that we only measured OP for the evaluation of the effects of smoking on the fluid dynamics of dental pulp tissue. Further studies are required to reveal the effects of smoking on other parameters together with the OP.

\section{Conclusion}

In dental pulp tissue, the OP decreased as the number of cigarettes smoked increased. This result may indirectly affect various pulpal reactions and inflammatory responses in smokers. Thus, clinical examination may lead to the misdiagnosis of pulpal conditions in smokers, even in healthy pulp tissue, due to the effect of altered the OP on pulpal tissue reactions.
References

Med Princ Pract 2015;24:465-469 DOI: $10.1159 / 000431325$
1 Ijzerman RG, Serne EH, van Weissenbruch MM, et al: Cigarette smoking is associated with an acute impairment of microvascular function in humans. Clin Sci (Lond) 2003; 104:247-252.

2 Fröhlich M, Sund M, Löwel H, et al: Independent association of various smoking characteristics with markers of systemic inflammation in men. Results from a representative sample of the general population (MONICA Augsburg Survey 1994/95). Eur Heart J 2003; 24:1365-1372.

-3 Reibel J: Tobacco and oral diseases. Med Princ Pract 2003;12:22-32.

-4 Sakallığlu EE, Ayas B, Sakallığlu U, et al: Osmotic pressure and vasculature of gingiva in periodontal disease: an experimental study in rats. Arch Oral Biol 2006;51:505-511. 
5 Auckland K, Fadnes HO: Protein concentration of interstitial fluid collected from rat skin by a wick method. Acta Physiol Scand 1973; 88:350-358.

6 Clarke NG, Shephard BC, Hirsch RS: The effects of intra-arterial epinephrine and nicotine on gingival circulation. Oral Surg Oral Med Oral Pathol 1981;52:577-582.

$\checkmark 7$ Ketabi M, Hirsch RS: The effects of local anesthetic containing adrenaline on gingival blood flow in smokers and non-smokers. J Clin Periodontol 1997;24:888-892.

$>8$ Feitelson JB, Rowell PP, Roberts CS, et al: Two week nicotine treatment selectively increases bone vascular constriction in response to norepinephrine. J Orthop Res 2003;21:497-502.

$>9$ Starling EH: On the absorption of fluids from the connective tissue spaces. J Physiol Lond 1896;19:312-326.

$>10$ Heyeraas KJ, Berggreen E: Interstitial fluid pressure in normal and inflamed pulp. Crit Rev Oral Biol Med 1999;10:328-336.

-11 Silness P, Löe H: Periodontal disease in pregnancy. Acta Odontol Scand 1964;22:121-135.

12 Löe H, Silness J: Periodontal disease in pregnancy. I. Prevalence and severity. Acta Odontol Scand 1963;21:533-551.
13 Auckland K, Johnsen HM: Protein concentration and colloid osmotic pressure of rat skeletal muscle interstitial fluid. Acta Physiol Scand 1974;91:354-364.

14 Sakallıŏ̆lu EE, Lütfioğlu M, Sakallıoğlu U, et al: Fluid dynamics of gingiva in diabetic and systemically healthy periodontitis patients. Arch Oral Biol 2008;53:646-651.

15 Lecerof H, Bornmyr S, Lilja B, et al: Acute effects of doxazosin and atenolol on smokinginduced peripheral vasoconstriction in hypertensive habitual smokers. J Hypertens Suppl 1990;8:S29-S33.

16 Bornmyr S, Svensson H: Thermography and laser-Doppler flowmetry for monitoring changes in finger skin blood flow upon cigarette smoking. Clin Physiol 1991;11:135-141.

17 Meekin TN, Wilson RF, Scott DA, et al: Laser Doppler flowmeter measurement of relative gingival and forehead skin blood flow in light and heavy smokers during and after smoking. J Clin Periodontol 2000;27:236-242.

18 Luukko K, Kettunen P, Fristad I, et al: Structure and function of the dentin-pulp complex; in Hargreaves KM, Cohen S (eds): Cohen's Pathways of the Pulps, ed 10. St Louis, Mosby Elsevier, pp 483-489.

-19 Sasano T, Kuriwada S, Sanjo D: Arterial blood pressure regulation of pulpal blood flow as determined by laser Doppler. J Dent Res 1989; 68:791-795.
20 Lindeboom JA, Mathura KR, Harkisoen S, et al: Effect of smoking on the gingival capillary density: assessment of gingival capillary density with orthogonal polarization spectral imaging. J Clin Periodontol 2005;32:1208-1212.

21 Awawdeh L, Lundy FT, Shaw C, et al: Quantitative analysis of substance $\mathrm{P}$, neurokinin A and calcitonin-gene related peptide in pulp tissue from painful and healthy human teeth. Int Endod J 2002;35:30-36.

22 Kim S: Regulation of pulpal blood flow. J Dent Res 1985;64:590-596.

23 Ajcharanukul O, Chunhacheevachaloke E, Vorachart P, et al: The postural autonomic regulation of pulpal blood flow. J Dent Res 2013;92:156-160.

24 Lorente de Nó R: Studies from the Rockefeller Institute for Medical Research. New York, Rockefeller Institute, 1947, vol 132.

25 Ahlquist ML, Franzen OG: Inflammation and dental pain in man. Endod Dent Traumatol 1994;10:201-209.

-26 Ahlquist M, Franzén O: Pulpal ischemia in man: effects on detection threshold, A-delta neural response and sharp dental pain. Endod Dent Traumatol 1999;15:6-16.

27 Krall EA, Sosa CA, Garcia C, et al: Cigarette smoking increases the risk of root canal treatment. J Dent Res 2006;85:313-317. 